\title{
Comparison of multiple models for estimating gross primary production using remote sensing data and fluxnet observations
}

\author{
SISI WANG ${ }^{1,2}$ \& XINGGUO MO ${ }^{1}$ \\ 1 Key Laboratory of Water Cycle and Related Land surface Processes, Institute of Geographic Sciences and Natural \\ Resources Research, Chinese Academy of Sciences, Beijing, 100101, China \\ moxg@igsnrr.ac.cn \\ 2 University of Chinese Academy of Sciences, Beijing, 100049, China
}

\begin{abstract}
In this study, gross primary production (GPP) estimated from a temperature and greenness (TG) model, a greenness and radiation (GR) model, a vegetation photosynthesis model (VPM), and a MODIS product have been compared with eddy covariance measurements in cropland during 2003-2005. Results showed that the determination coefficients $\left(\mathrm{R}^{2}\right)$ between fluxnet GPP and estimated GPP were all greater than 0.74 , indicating that all these models offered reliable estimates of GPP. We also found that the VPMbased GPP estimates performed a bit better $\left(\mathrm{R}^{2}\right.$ is 0.82 , and RMSE is $\left.16.75 \mathrm{gC} \mathrm{m}^{-2}(8 \mathrm{day})^{-1}\right)$ than other models, mainly due to its comprehensive consideration of the stresses from light, temperature and water. The actual GPP was overestimated in the non-growing season and underestimated in the growing season by MOD_GPP. The validation confirms that the above three models may be used to estimate crop production in the North China Plain, but there are still significant uncertainties.
\end{abstract}

Key words gross primary production (GPP); VPM; GR; TG; cropland

\section{INTRODUCTION}

As an important variable in the global carbon cycle, gross primary productivity (GPP) is defined as the overall photo-synthetic fixation of carbon per unit space and time. Prior studies showed that approximately $12 \%$ of Earth's land surface was cultivated cropland and crop GPP accounted for approximately $15 \%$ of global carbon dioxide fixation (Malmström et al., 1997). Therefore, accurate and synoptic GPP estimates in cropland can offer useful information for global carbonwater cycle studies and agricultural applications.

The eddy covariance (EC) technique provides net $\mathrm{CO}_{2}$ exchange which can be used for developing and validating GPP models. Satellite remote sensing at moderate spatial resolutions can provide consistent observations of land surface properties over large areas and has become more and more importance for GPP estimates (Wu, 2012; Zhang et al., 2012). Recently, a number of remote sensing based GPP models have been proposed and widely used for GPP simulation at different scales, among which the temperature and greenness (TG), greenness and radiation (GR) and vegetation photosynthesis model (VPM) are characterized by the advantages of fewer parameters and high accuracy. The GR model applies remote estimation of chlorophyll content for retrieval of the GPP, which provides a robust estimation of midday GPP (Gitelson et al., 2006). The TG model combines EVI and LST and improves the correlation between the estimated and observed data (Sims et al., 2008). Both the GR and TG models were developed based entirely on remote sensing data and are independent of climate variables. The VPM model is built based on the conceptual partitioning of photosynthetically-active vegetation and non-photosynthetic vegetation within the leaf and canopy, and highlight the biophysical performance of improved vegetation indices in relation to GPP (Xiao et al., 2004). Although all these models performed well in vegetation for specific areas, they have substantial variations and uncertainties in GPP estimation and should be further evaluated in cropland for China.

In this study, GPP in cropland estimated from the TG model, GR model, VPM model and MODIS GPP product have been compared with each other for the period 2003-2005, using climate variables from fluxnet observations (Yucheng site) and MODIS data. The aim is to assess each GPP simulation model and find the optimal one for simulating the GPP in cropland in the North China plain. 


\section{METHODS}

\subsection{Study area}

Yucheng eddy flux tower site $\left(36^{\circ} 50^{\prime} \mathrm{N}\right.$ and $\left.116^{\circ} 34^{\prime} \mathrm{E}\right)$ is located in the central North China Plain, on an alluvial plain (elevation $28 \mathrm{~m}$ ) developed by the intermittent flooding of the Yellow River. The soil texture of this site is light loam or medium loam. It has a semi-humid continental monsoon climate in the warm Temperate Zone, with four distinct seasons and plenty of sunshine. The dominant land use is cropland with the prevailing double-cropping system of winter wheat (Triticum aestivum L.) and summer maize (Zea mays L.). As the major agricultural region in North China Plain, Yucheng has great potential for agricultural production. The annual mean temperature is $13.1^{\circ} \mathrm{C}$ and the annual mean precipitation is about $582 \mathrm{~mm}$.

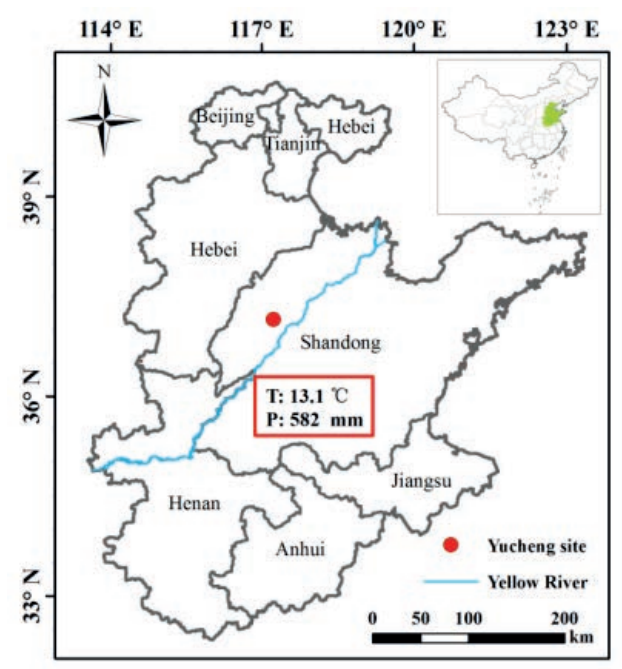

Fig. 1 The location of Yucheng site in NCP.

\subsection{Data}

\subsubsection{Meteorological data and $\mathrm{CO}_{2}$ flux data}

The meteorological and net $\mathrm{CO}_{2}$ exchange flux data used in this study are downloaded from the Chinese Ecosystem Research Network (http://www.cern.ac.cn/). It provides the meteorological and flux datasets at half hourly intervals. First, meteorological and net $\mathrm{CO}_{2}$ exchange flux data from 2003 to 2005 are aggregated into daily values; then, in order to be compatible with the remotely sensed data, the daily datasets are further aggregated into 8-day intervals.

For calibrating and validating the GPP models, 8-day flux observed data are used. All effective measurements are divided into two groups: one for model calibration, including $70 \%$ of all the data (randomly chosen) and the remainder for validation.

\subsubsection{Remote sensing data}

The Moderate Resolution Imaging Spectroradiometer (MODIS) data used in the study can be categorized as: (1) the land surface reflectance product; (2) the land surface temperature (LST) product; and (3) the GPP product.

MODIS 8-day surface reflectance product (MOD09A1) is computed from the MODIS Level 1B land bands: red (620-670 nm), NIR 1 (841-876 nm), blue $(459-479 \mathrm{~nm})$, green $(545-565 \mathrm{~nm})$, $\mathrm{NIR}_{2}(1230-1250 \mathrm{~nm}), \mathrm{SWIR}_{1}(1628-1652 \mathrm{~nm})$, and $\mathrm{SWIR}_{2}(2105-2155 \mathrm{~nm})$ (Vermote et al., 1997) with a resolution of $500 \mathrm{~m}$.

MODIS 8-day LST/Emissivity product (MOD11A2) is composed from the daily 1-kilometre LST product (MOD11A1) and stored on 1-km pixels as the average values of clear-sky LSTs during an 8-day period. 
The MODIS 8-day GPP product (MOD17A2) is continuous remote sensing-driven data with $1 \mathrm{~km}$ spatial resolution across the globe. The algorithm used to estimate GPP in MOD17A2 is described in Zhao et al. (2005).

Based on the latitude and longitude of the Yucheng sites, remote sensing data at 8-day composites are finally extracted from $3 \times 3 \mathrm{~km}(3 \times 3$ pixels for $1-\mathrm{km}$ spatial resolution data and $6 \times 6$ pixels for 500-m spatial resolution data) around the centre of the flux tower (Fu et al., 2014).

\subsubsection{Vegetation and water index}

In this study, the two indices used are calculated from blue, red, NIR 1 , and SWIR 1 bands. The first is the Enhanced Vegetation Index (EVI) (Huete et al., 1997):

$$
E V I=2.5 \times \frac{\rho_{N I R 1}-\rho_{\text {red }}}{1+\rho_{\text {NIR1 }}+6 \times \rho_{\text {red }}-7.5 \times \rho_{\text {blue }}}
$$

The second is the Land Surface Water Index (LSWI) (Xiao et al., 2002):

$$
L S W I=\frac{\rho_{N I R 1}-\rho_{S W I R 1}}{\rho_{N I R 1}+\rho_{S W I R 1}}
$$

\subsection{Models and analysis methods}

In the study, the TG model, GR model, and VPM model are used for the estimation of GPP in cropland during 2003-2005. The parameters used in these models are LST\&EVI (TG), EVI\&PAR (GR), and EVI\&PAR\& $f(T) \& f(W)(V P M)$, respectively; $f(T)$ and $f(W)$ are down-regulation scalars for the effects of temperature and water in VPM model.

To evaluate model performance, the determination coefficient $\left(\mathrm{R}^{2}\right)$, root mean square error (RMSE), Pearson correlation coefficient (r), and bias (the difference between simulations and observations) are used in this study.

\section{RESULTS AND DISCUSSION}

\subsection{Calibration and validation for each model}

Table 1 shows the statistical summaries for the results of GR, TG and VPM in calibration and validation. All these models behave well for Yucheng in the period of calibration, indicating that they have potential to capture the physical process of GPP variations. While the GR model overestimates the observed GPP (OBS GPP) a little, TG and VPM slightly underestimate the OBS_GPP. In the process of model validation, the three GPP models also perform well with $\mathrm{R}^{2}$ generally larger than those in model calibration. From this analysis we can conclude that these models can be used for GPP estimations in cropland.

Table 1 Models performances in calibration and validation.

\begin{tabular}{llrll}
\hline & Models & Bias & RMSE & $\mathrm{R}^{2}$ \\
\hline Calibration & GR & 8.82 & 21.69 & 0.76 \\
& TG & -2.30 & 21.81 & 0.70 \\
& VPM & -4.44 & 19.20 & 0.78 \\
\hline Validation & GR & 8.53 & 14.61 & 0.91 \\
& TG & -4.22 & 16.20 & 0.83 \\
& VPM & -4.42 & 12.42 & 0.91 \\
\hline
\end{tabular}

*The units of bias and RMSE are $\left(\mathrm{gC} \mathrm{m}^{-2}(8 \text { day })^{-1}\right)$.

\subsection{GPP simulation from GR model}

GPP simulated by the GR model (GR_GPP) is compared with the OBS_GPP for Yucheng site in 2003, 2004 and 2005 (Fig. 2(a)). The RMSE between GR_GPP and OBS_GPP are 14.66, 19.92 and $23.41 \mathrm{gC} \mathrm{m}^{-2}(8 \mathrm{day})^{-1}$ for each year respectively, with $\overline{\mathrm{R}}$ of $0.953,0.879$ and $0.864(\mathrm{P}<0.01)$. 
Figure 3 shows that the evolution of GR_GPP is consistent with that of OBS_GPP basically in all three years, and especially in 2003. Nevertheless, actual GPP is still slightly overestimated by GR_GPP in the non-growing season, which is because in the non-growing season, OBS_GPP generally equals zero, whereas PAR and EVI used in the GR model are greater than zero over the whole year.
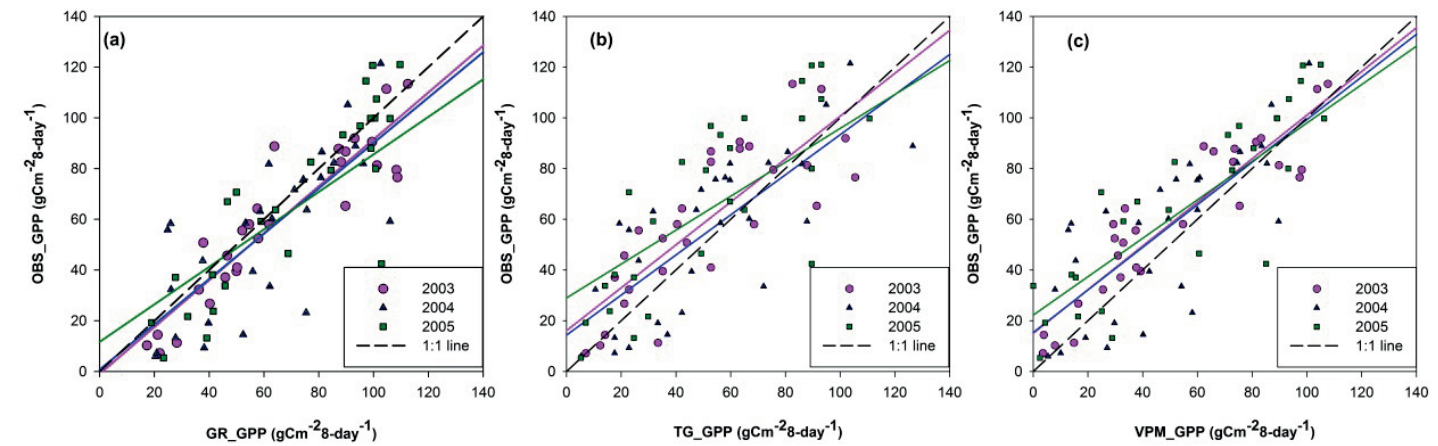

Fig. 2 Relations between (a) GR_GPP / (b) TG_GPP / (c) VPM_GPP and OBS_GPP in Yucheng site from 2003 to 2005 . All correlations are significant at the 0.01 level.

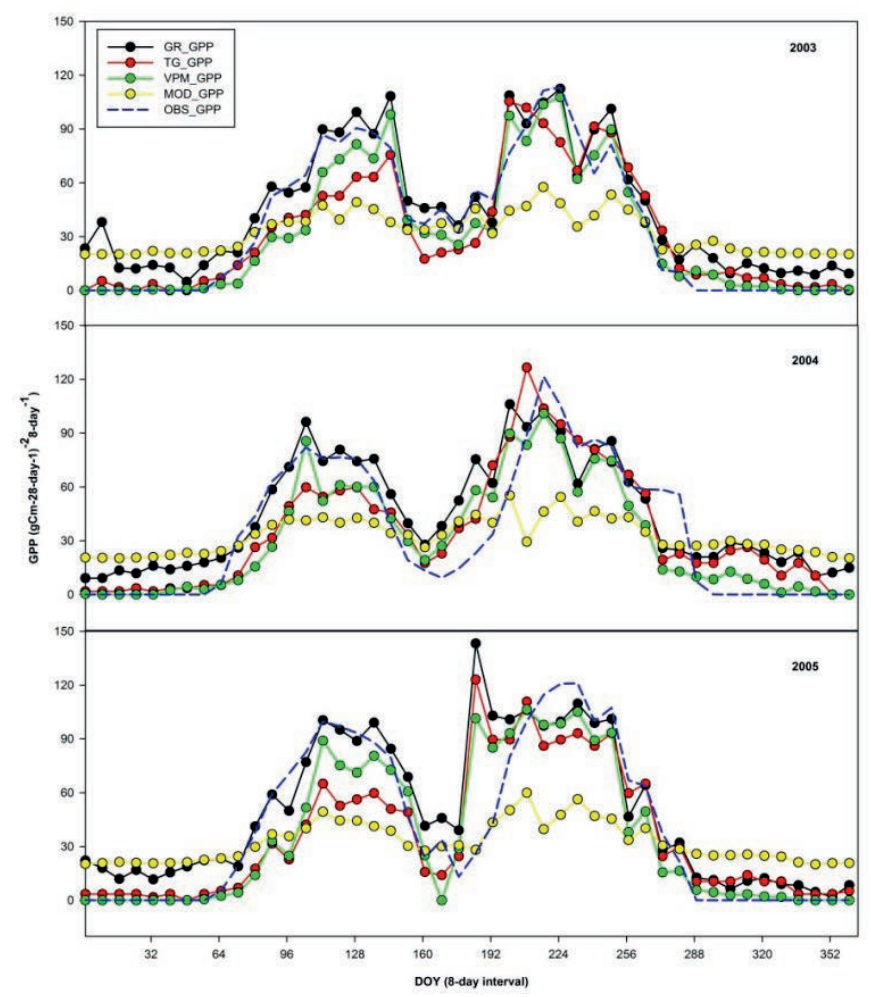

Fig. 3 The 8-day evolution of the observed GPP (OBS_GPP), MODIS GPP product (MOD_GPP), GPP simulated by GR model (GR GPP), GPP simulated by TG model (TG_GPP), and GPP simulated by VPM model (VPM_GPP) in Yucheng site from 2003 to 2005.

\subsection{GPP simulation from TG model}

GPP simulated by the TG model (TG_GPP) is compared with the OBS_GPP for Yucheng site in 2003, 2004 and 2005, respectively (Fig. 2(b)). The RMSE values between TG_GPP and OBS_GPP are $15.58,18.05$ and $24.62 \mathrm{gC} \mathrm{m}^{-2}(8 \text { day })^{-1}$ for each year respectively, with $\overline{\mathrm{R}}$ of 0.913 , $0.86 \overline{6}$ and $0.818(\mathrm{P}<0.01)$. In Fig. 3 , in the non-growing season, TG_GPP performs dramatically better than MOD_GPP and GR_GPP, when compared with OBS_GPP. However, in the growing 
season, actual GPP is underestimated by TG GPP in all three years due to the limitation of LST. $\mathrm{Wu}$ et al. (2010) found that, the accuracy of estimated GPP was clearly improved when air temperature was used in TG instead of LST.

\subsection{GPP simulation from VPM model}

GPP simulated from the VPM model (VPM_GPP) is compared with the OBS_GPP for Yucheng site in 2003, 2004 and 2005 (Fig. 2(c)). It is showed that RMSE between VPM_GPP and OBS_GPP are $11.76,17.71$ and $19.74 \mathrm{gC} \mathrm{m}^{-2}(8 \mathrm{day})^{-1}$ for each year, respectively, with high $\mathrm{R}$ of $0.95 \overline{5}, 0.878$ and $0.891(\mathrm{P}<0.01)$. According to Fig. 3, VPM_GPP perfectly catches the yearly evolution of OBS_GPP both in the growing and non-growing seasons; this is mainly due to its comprehensive consideration of the limitations of light, temperature and water.

\subsection{The performance of MOD_GPP and intercomparison of GPP simulated by different models with MOD_GPP}

MODIS GPP product (MOD_GPP) with 8-day interval is validated against the OBS_GPP for Yucheng site in 2003, 2004 and 2005. RMSE between MOD_GPP and OBS_GPP are 27.22, 29.12 and $33.34 \mathrm{~g} \mathrm{Cm}^{-2}(8 \mathrm{day})^{-1}$ for each year respectively, with $\mathrm{R}$ of $0.945,0.794$ and 0.93 , all of which pass significance level $(\alpha)$ of $0.01(\mathrm{P}<0.01)$. According to Fig. 3, MOD_GPP is larger than OBS_GPP below $30 \mathrm{gC} \mathrm{m}^{-2}(8 \mathrm{day})^{-1}$, and smaller than OBS_GPP above $30 \mathrm{gC} \mathrm{m}^{-2}(8 \mathrm{day})^{-1}$, indicating that the actual GPP value is overestimated in the non-growing season (DOY around 0 80, 160-200, and 280-365) and underestimated in the growing season (DOY around 81-159 and 201-279). The unsatisfactory result from MOD_GPP may be mainly caused by the coarse resolution of the environmental stress factors used in the algorithm (Heinsch et al., 2006; Sims et al., 2006).

To understand which model has the best performance for GPP simulation in cropland for the North China Plain, the annual mean GPP is calculated for each model, MODIS product and in situ observations during 2003-2005 (Table 2). The annual mean OBS_GPP is $1706.59 \mathrm{gC} \mathrm{m}^{-2}$ year-1, $^{-1}$, and the value of annual mean TG_GPP is the closest to OBS_GPP at $1605.9 \mathrm{gC} \mathrm{m}^{-2}$ year $^{-1}$. The annual mean GPP is obviously underestimated by MOD GPP and overestimated by GR GPP. The bias, RMSE, and $\mathrm{R}^{2}$ between OBS_GPP and model simulated GPP / MOD_GPP are also calculated. It seems that TG_GPP has the smallest bias as $-2.19 \mathrm{gC} \mathrm{m}^{-2}$ (8day) $)^{-1}$, and VPM_GPP has the smallest RMSE as $1 \overline{6} .75 \mathrm{gC} \mathrm{m}^{-2}(8 \mathrm{day})^{-1}$. Meanwhile, VPM_GPP has the highest $\mathrm{R}^{2}, 0.82$, indicating that VPM is a valuable tool for estimating GPP of cropland in North China Plain. Although $\mathrm{R}^{2}$ between MOD_GPP and OBS_GPP are relatively high at 0.796 , actual GPP is overestimated in the non-growing season and underestimated in the growing season with an RMSE of $30 \mathrm{gC} \mathrm{m}^{-2}$ (8day) ${ }^{-1}$, indicating that the quality of MOD_GPP needs to be further improved for the analysis in cropland of the North China Plain.

Table 2 Bias, root mean square error (RMSE), and coefficients of determination $\left(\mathrm{R}^{2}\right)$ between MOD_GPP / GR_GPP / TG_GPP / VPM_GPP and OBS_GPP in Yucheng site from 2003 to 2005.

\begin{tabular}{lllll} 
Correlations with & $\begin{array}{l}\text { Annual mean GPP } \\
\left(\mathrm{gC} \mathrm{m}^{-2} \text { year }^{-1}\right)\end{array}$ & $\begin{array}{l}\text { Bias } \\
\left(\mathrm{gC} \mathrm{m}^{-2}\left(8 \text { day }^{-1}\right)\right.\end{array}$ & $\begin{array}{l}\mathrm{RMSE} \\
\left(\mathrm{gC} \mathrm{m}^{-2}(8 \mathrm{day})^{-1}\right)\end{array}$ & $\mathrm{R}^{2}$ \\
\hline MOD_GPP & 1484.30 & 4.83 & 30.00 & 0.80 \\
GR_GPP & 2145.88 & 9.55 & 19.66 & 0.80 \\
TG_GPP & 1605.90 & -2.19 & 19.79 & 0.74 \\
VPM_GPP & 1517.45 & -4.11 & 16.75 & 0.82 \\
\hline
\end{tabular}

*The annual mean OBS_GPP is $1706.59 \mathrm{gC} \mathrm{m}^{-2}$ year $^{-1}$. All correlations are significant at the 0.01 level.

\section{CONCLUSIONS}

This paper compared the correlation between TG_GPP, GR_GPP, VPM_GPP, MOD_GPP and OBS_GPP in cropland of the Yucheng site during the period of 2003-2005. The results showed 
that $\mathrm{R}^{2}$ between OBS GPP and TG GPP, GR GPP, VPM GPP equalled $0.74,0.80$ and 0.82 , respectively. And all RMSE between OBS GPP and GPP estimated by the models were smaller than $20 \mathrm{gC} \mathrm{m}^{-2}$ (8day) $)^{-1}$, and bias values were within $\pm 10 \mathrm{gC} \mathrm{m}^{-2}$ (8day) ${ }^{-1}$ indicating that all these models offer reliable estimates of actual GPP. We also found that the VPM GPP performed a bit better $\left(\mathrm{RMSE}=16.75 \mathrm{gC} \mathrm{m}^{-2}(8 \mathrm{day})^{-1}\right.$ and $\left.\mathrm{R}^{2}=0.82\right)$ than the other models with smaller RMSE and higher $\mathrm{R}^{2}$ compared with OBS GPP, mainly due to its comprehensive consideration of the limitations of light, temperature and water. Despite the small bias of $4.83 \mathrm{gC} \mathrm{m}^{-2}(8 \mathrm{day})^{-1}$, actual GPP was overestimated in the non-growing season and underestimated in the growing season by MOD_GPP, with an RMSE of $30.00 \mathrm{gC} \mathrm{m}^{-2}(8 \text { day })^{-1}$. This study suggests that the above three models may be used to estimate crop production in the North China Plain, but there are still significant uncertainties.

Acknowledgements This study was jointly supported by the Natural Science Foundation of China grants (31171451), the Key Project for the Strategic Science Plan in IGSNRR, CAS (2012ZD003) and the Chinese Ministry of Science and Technology Projects (2010CB428404).

\section{REFERENCES}

Fu, D., et al. (2014) Estimating landscape net ecosystem exchange at high spatial-temporal resolution based on Landsat data, an improved upscaling model framework, and eddy covariance flux measurements. Remote Sens. Environ. 141, 90-104.

Gitelson, A. A., et al. (2006) Relationship between gross primary production and chlorophyll content in crops: Implications for the synoptic monitoring of vegetation productivity. J. Geophys. Res.-Atmos. 111, D08S11, doi:10.1029/2005JD006017.

Heinsch, F. A., et al. (2006) Evaluation of remote sensing based terrestrial productivity from MODIS using regional tower eddy flux network observations. Geoscience and Remote Sensing, IEEE Transactions on 44, 1908-1925.

Huete, A. R., et al. (1997) A comparison of vegetation indices over a global set of TM images for EOS-MODIS. Remote Sens. Environ. 59, 440-451.

Malmström, C. M., et al. (1997) Interannual variation in global-scale net primary production: Testing model estimates. Global Biogeochem. Cy. 11,367-392.

Sims, D. A., et al. (2006) On the use of MODIS EVI to assess gross primary productivity of North American ecosystems. J. Geophys. Res.-Biogeo. 111, G04015.

Sims, D. A., et al. (2008) A new model of gross primary productivity for North American ecosystems based solely on the enhanced vegetation index and land surface temperature from MODIS. Remote Sens. Environ. 112, $1633-1646$.

Vermote, E. F., et al. (1997) Atmospheric correction of visible to middle-infrared EOS-MODIS data over land surfaces: Background, operational algorithm and validation. J. Geophys. Res.-Atmos. 102, 17131-17141.

$\mathrm{Wu}, \mathrm{C}$. , (2012) Use of a vegetation index model to estimate gross primary production in open grassland. J. Appl. Remote Sens. 6(1), 063532-1-063532-11.

$\mathrm{Wu}, \mathrm{C}$, et al. (2010) Comparison of multiple models for estimating gross primary production using MODIS and eddy covariance data in Harvard Forest. Remote Sens. Environ. 114, 2925-2939.

Xiao, X., et al. (2002) Observation of flooding and rice transplanting of paddy rice fields at the site to landscape scales in China using VEGETATION sensor data. Int. J. Remote Sens. 23, 3009-3022.

Xiao, X., et al. (2004) Modeling gross primary production of temperate deciduous broadleaf forest using satellite images and climate data. Remote Sens. Environ. 91, 256-270.

Zhang, F., et al. (2012) Evaluating spatial and temporal patterns of MODIS GPP over the conterminous US against flux measurements and a process model. Remote Sens. Environ. 124, 717-729.

Zhao, M., et al. (2005) Improvements of the MODIS terrestrial gross and net primary production global data set. Remote Sens. Environ. 95, 164-176. 